\title{
Dietary intakes of starch and non-starch polysaccharides in a West African village
}

\author{
BY GEOFFREY J. HUDSON AND HANS N. ENGLYST \\ MRC Dunn Clinical Nutrition Centre, Hills Road, Cambridge CB2 $2 D H$
}

(Received 4 January 1994 - Revised 12 September 1994 - Accepted 4 October 1994)

\begin{abstract}
Dietary intakes of starch and non-starch polysaccharides (NSP) have been estimated for a rural West African community. These people eat directly from shared bowls of cooked food, and so measurement of any individual's food intake is not possible. Recently developed methodology for estimating food intake under these circumstances and the analysis of samples for dietary polysaccharides are combined to yield estimates of intakes of about $375 \mathrm{~g}$ starch and $25 \mathrm{~g} \mathrm{NSP} / \mathrm{d}$ for adult males, with lower intakes for women and children, related to their smaller body weights. These intakes are not direct measurements but are extremely plausible when compared with values obtained for other societies where the complication of the shared food bowl does not impinge upon the measurements.
\end{abstract}

West Africa: Non-starch polysaccharides: Starch: Dietary intakes

Direct measurements of an individual's dietary intake cannot be made when groups of people eat from shared bowls of food but reasonable values for food intake may be obtained by the application of appropriate methodology (Hudson, 1992, 1995). The method consists of weighing and recording every ingredient during the preparation of cooked food, weighing the cooked food and weighing the people who are going to eat the food. Food-table values are then used to calculate the nutrient content of the meal. The division of food between the subjects is estimated, taking account of body weight and applying a mathematical weighting factor in recognition of the fact that intake is not directly proportional to body weight (Anderson et al. 1977). When energy intakes from two cooked meals per $\mathrm{d}$ are calculated in this way for subjects living in the village of Keneba in The Gambia, West Africa, they are shown to represent $80 \%$ of total energy expenditure as measured by the doubly labelled water technique (Hudson, 1992, 1995). The present paper presents the results of applying the same methodology for calculation of the intakes of starch and of non-starch polysaccharides (NSP, dietary fibre) in this rural West African community.

\section{MATERIALS AND METHODS}

The studies took place from 1987 to 1989 in the farming villages of Keneba, Kanton Kunda and Manduar in the West Kiang District of The Gambia, West Africa. All family members took part in the measurement of food intake but only those who were at least 13 years old took part in other parts of the study. Ethical permission for the work was granted by the joint Medical Research Council/Gambian Government Scientific Coordinating Committee and Ethical Committee. A detailed description of this work has been given elsewhere (Hudson, 1992, 1995). Qualitative and quantitative data were collected for the ingredients 
Table 1. Total starch* content ( $\mathrm{g} / \mathrm{kg}$ dry matter) of Gambian foods $\dagger$

\begin{tabular}{|c|c|c|c|}
\hline \multicolumn{2}{|c|}{ Starch (g/kg) } & \multicolumn{2}{|c|}{ Starch $(\mathrm{g} / \mathrm{kg})$} \\
\hline Vegetables & & Cereals & \\
\hline Bush cassava & & Wheat flour & 788 \\
\hline Raw & 763 & Maize & \\
\hline Boiled & 745 & Whole & 696 \\
\hline Cassava, raw & 711 & Dehusked & 760 \\
\hline Beans (cowpea), raw & 470 & Flour & 723 \\
\hline Potato, raw & 720 & Rice & \\
\hline Aubergine, raw & 80 & Whole & 616 \\
\hline Bitter tomato, raw & 63 & Dehusked & 812 \\
\hline Okra, raw & 114 & Flour & 825 \\
\hline Palm kernel, raw & 4 & Dempetengo & 796 \\
\hline Groundnuts & & Findo millet & \\
\hline Raw & 29 & Whole & 609 \\
\hline Roast & 32 & Dehusked & 850 \\
\hline Fruit & & Sanyo millet & \\
\hline Locust beans, raw & 7 & Dehusked & 681 \\
\hline Locust bean pod, raw & 5 & Flour & 701 \\
\hline Mango unripe, raw & 533 & Sorghum & \\
\hline Baobab flesh, raw & 16 & Whole & 707 \\
\hline Pawpaw, raw & 0 & Flour & 777 \\
\hline Bush mango, raw & 126 & Suno millet & \\
\hline Tamba, raw & 30 & Whole & 658 \\
\hline Tubabu ningkongo & 365 & Flour & 711 \\
\hline
\end{tabular}

* Starch is expressed as glucose $\times 0.89$.

$\dagger$ For botanical names, see Table 2.

of cooked food and the weight of the cooked food was established. Food was weighed on portable electronic scales to the nearest $1 \mathrm{~g}$. The people who were to eat the food were weighed, to the nearest $100 \mathrm{~g}$ on portable electronic scales, whenever possible, and their age and sex were recorded. These measurements were made in the subjects' compound and made minimal demands on their time.

Samples (approximately $150 \mathrm{ml}$ ) of raw and cooked food were collected in Keneba in exchange for rice, freeze-dried where appropriate, and sent to Cambridge for analysis. Total starch was measured by the method of Englyst \& Kingman (1990). NSP were measured by the method of Englyst et al. (1992b). Data from the field records and from the food analysis are stored on the University of Cambridge mainframe computer and have been analysed in the SIR system using programs written under the guidance of $\mathrm{Mr} \mathrm{K}$. C. Day, Dunn Nutrition Unit, Cambridge. The compositional values are used in conjunction with the field records to calculate the nutrient content of the cooked food, and the distribution of it is estimated by dividing it between subjects, assuming a distribution of food that recognizes a non-proportional relationship between energy requirements and body weights (Anderson et al. 1977). Mathematical factors are calculated for each sex $(X) /$ age $(Y)$ classification using the algorithm:

$$
\left.X / Y \text { factor }={ }^{\text {int }}\left(\left(W_{t}-10 \cdot 5\right) / 10\right)\right) \times 0 \cdot 25+1 \cdot 5,
$$

where ${ }^{\text {int }}(x)$ is the integer of $x$ and $W_{t}$ is body weight $(\mathrm{kg})$ for individuals who weigh more than $10.5 \mathrm{~kg}$; subjects who weigh less than $10.5 \mathrm{~kg}$ are assigned a factor of 1.0 . 

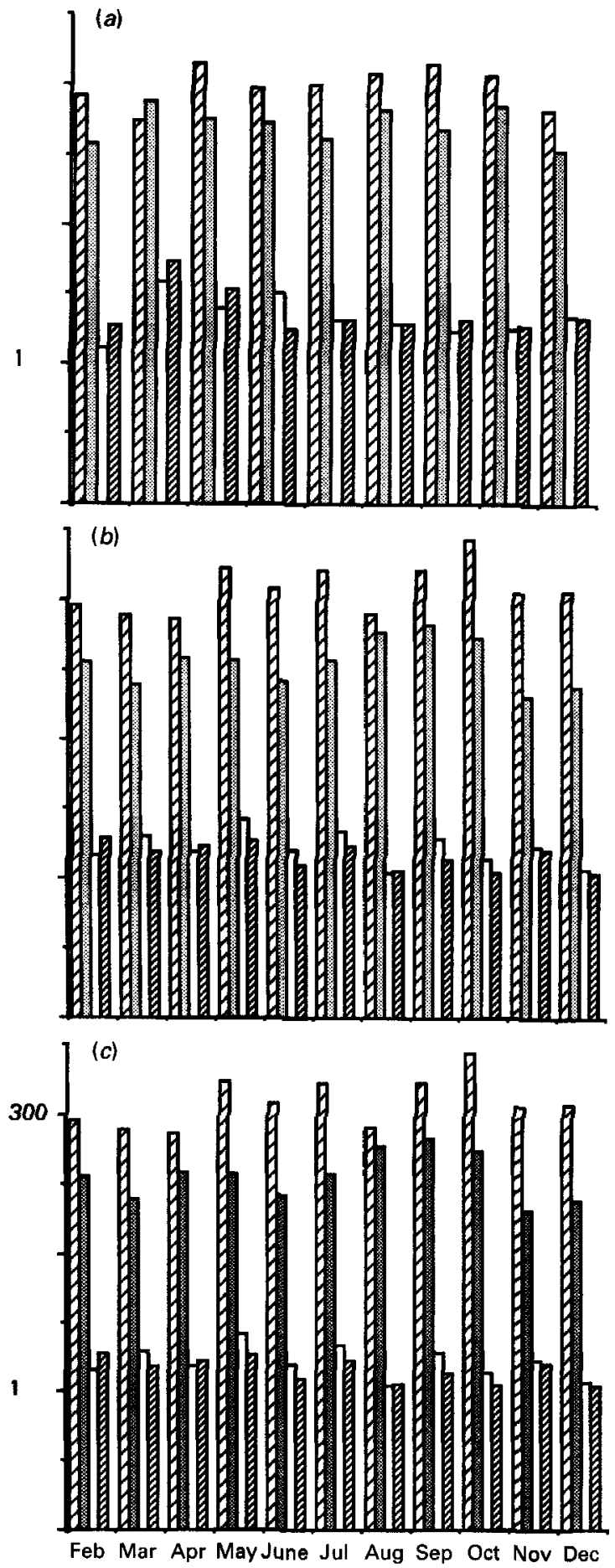

Fig. 1. Mean starch intakes from cooked food for men ( $\square$ ), women (图), boys ( $\square$ ) and girls (圆) in West Africa during the years (a) 1987, (b) 1988 and (c) 1989. Intakes are $g$ starch/d, calculated as twice the mean over all observed meals for each month. 
Table 2. Non-starch polysaccharide ( $N S P$ ) content of Gambian foods ( $\mathrm{g} / \mathrm{kg}$ dry matter)

(Values are shown for total NSP, insoluble NSP separated into cellulose and non-cellulosic polysaccharides (NCP) and soluble NSP which is calculated as the difference between total and insoluble NSP)

\begin{tabular}{|c|c|c|c|c|}
\hline & \multirow{2}{*}{$\begin{array}{c}\text { Soluble } \\
\text { NSP }\end{array}$} & \multicolumn{2}{|c|}{ Insoluble NSP } & \multirow{2}{*}{$\begin{array}{l}\text { Total } \\
\text { NSP }\end{array}$} \\
\hline & & Cellulose & NCP & \\
\hline \multicolumn{5}{|l|}{ Leaves } \\
\hline Baobab (Adansonis digitata) & 170 & 48 & 81 & 299 \\
\hline Bitter tomato (Solanum incanum) & 75 & 42 & 33 & 150 \\
\hline Cassava (Manihot esculenta) & 85 & 63 & 50 & 198 \\
\hline Groundnut (Arachis hypogaea) & 87 & 68 & 67 & 222 \\
\hline Jambanduro (Cassia tora) & 120 & 54 & 52 & 226 \\
\hline Kerenkerengo (Corchorus olitorius) & 174 & 55 & 38 & 267 \\
\hline Kucha (Hibiscus sabdariffa) & 117 & 69 & 62 & 248 \\
\hline Morongo (Amaranthus sp. (caudatus/viridis)) & 81 & 59 & 66 & 206 \\
\hline Nebedayo (Moringo oleifera) & 104 & 42 & 43 & 189 \\
\hline Pumpkin (Cucurbita maxima) & 100 & 48 & 37 & 185 \\
\hline Sweet potato (Ipomaea batatas) & 118 & 67 & 49 & 234 \\
\hline Sobo (unidentified leaf) & 186 & 48 & 62 & 296 \\
\hline Sora (Leptadenia sp. (lancifolia/hastata)) & 167 & 76 & 63 & 306 \\
\hline \multicolumn{5}{|l|}{ Vegetables } \\
\hline Aubergine (Solanum melongena) & 158 & 108 & 59 & 325 \\
\hline Bitter tomato & 171 & 106 & 53 & 330 \\
\hline $\begin{array}{l}\text { Bush cassava (Dioscorea sp. } \\
\text { (prahensalis/bulbifera)) }\end{array}$ & 17 & 12 & 16 & 45 \\
\hline Cassava & 46 & 25 & 24 & 95 \\
\hline Chilli pepper (Capsicum frutescens) & 59 & 38 & 151 & 248 \\
\hline Green beans (cowpea; Vigna unguiculata) & 29 & 18 & 38 & 85 \\
\hline \multicolumn{5}{|l|}{ Groundnuts } \\
\hline Fresh & 24 & 20 & 33 & 77 \\
\hline Roast & 14 & 16 & 33 & 63 \\
\hline Okra (Hibiscus esculentus) & 161 & 56 & 49 & 266 \\
\hline Onion (Alium cepa) & 111 & 44 & 22 & 177 \\
\hline Potato (Solanum tuberosum) & 19 & 19 & 10 & 48 \\
\hline Pumpkin & 64 & 65 & 37 & 166 \\
\hline Spring onion & 121 & 59 & 23 & 203 \\
\hline Tomato & 82 & 47 & 45 & 174 \\
\hline Tomato paste & 56 & 66 & 25 & 147 \\
\hline Wonjo (Hibiscus sp.) & 170 & 107 & 88 & 365 \\
\hline \multicolumn{5}{|l|}{ Fruit } \\
\hline Cashew apple (Anaccerdium occidentale) (s) & 56 & 36 & 22 & 114 \\
\hline Locust bean seeds (Parkia biglobosa) & 139 & 89 & 73 & 301 \\
\hline Locust beans, dehusked & 42 & 19 & 12 & 73 \\
\hline \multicolumn{5}{|l|}{ Mango (Mangifera indica) } \\
\hline Ripe flesh (s) & 64 & 27 & 11 & 102 \\
\hline Ripe with skin (s) & 102 & 25 & 13 & 140 \\
\hline Unripe flesh (s) & 85 & 18 & 25 & 128 \\
\hline Unripe with skin (s) & 80 & 23 & 53 & 156 \\
\hline Palm kernel (Elaeis guineensis) & 36 & 25 & 190 & 251 \\
\hline Pawpaw (Carica papaya) (s) & 121 & 74 & 41 & 236 \\
\hline \multicolumn{5}{|l|}{ Cereals } \\
\hline \multicolumn{5}{|l|}{ Findo millet (Digitaria exilis) } \\
\hline Whole grain & 6 & 42 & 49 & 97 \\
\hline Dehusked & 3 & 3 & 4 & 10 \\
\hline \multicolumn{5}{|l|}{ Maize (Zea mays) } \\
\hline Whole kernels & 36 & 3 & 121 & 160 \\
\hline Dehusked & 10 & 17 & 44 & 71 \\
\hline Flour & 8 & 10 & 27 & 45 \\
\hline
\end{tabular}


Table 2. (cont.)

\begin{tabular}{|c|c|c|c|c|}
\hline & \multirow{2}{*}{$\begin{array}{l}\text { Soluble } \\
\text { NSP }\end{array}$} & \multicolumn{2}{|c|}{ Insoluble NSP } & \multirow{2}{*}{$\begin{array}{l}\text { Total } \\
\text { NSP }\end{array}$} \\
\hline & & Cellulose & NCP & \\
\hline \multicolumn{5}{|l|}{ Rice (Oryza sativa) } \\
\hline Whole grain & 3 & 70 & 55 & 128 \\
\hline Dehusked & 13 & 6 & 7 & 26 \\
\hline Flour & 2 & 3 & 5 & 10 \\
\hline Dempetengo & 4 & 6 & 11 & 21 \\
\hline \multicolumn{5}{|c|}{ Sanyo millet (Pennisetum typhoideum) } \\
\hline Whole grain & 25 & 6 & 84 & 115 \\
\hline Dehusked & 13 & 18 & 52 & 83 \\
\hline Flour & 7 & 8 & 28 & 43 \\
\hline \multicolumn{5}{|l|}{$\begin{array}{l}\text { Sorghum (Sorghum sp. } \\
\text { (gambicum/margaritiferum)) }\end{array}$} \\
\hline Whole grain & 4 & 17 & 44 & 65 \\
\hline Flour & 2 & 3 & 13 & 18 \\
\hline \multicolumn{5}{|l|}{ Suno millet (Pennisetum gambiense) } \\
\hline Whole grain & 11 & 21 & 53 & 85 \\
\hline Flour & 32 & 23 & 34 & 89 \\
\hline Wheat (Triticum aestivum), flour & 14 & 3 & 14 & 31 \\
\hline
\end{tabular}

(s), Snack food.

\section{RESULTS AND DISCUSSION}

Starch measurement

Representative samples of individual food types were collected in Keneba and were analysed for their total starch content by the method of Englyst \& Kingman (1990). The analytical values are shown in Table 1 . These total starch values were entered into the database and starch intakes from the two cooked meals were calculated using the same arithmetic as that used for the calculation of energy intakes (Hudson, 1992). The results for each month for men, women, boys and girls in 1987, 1988 and 1989 are illustrated by Fig. 1.

The mean starch intake ( $\mathrm{g} / \mathrm{d}$ for two cooked meals) in 1989 , as the average over 10 months (excluding April and May), was 311.4 (SD 11.5) for men, 258.1 (SD 16.8) for women, 134.3 (SD 7.4) for boys and 122.9 (SD 5.4) for girls. Two meals, 'lunch' and 'dinner', were studied each day; considering only the intakes of starch for men, the mean intake over the 10 months was 177.7 (sD 9.0) $\mathrm{g}$ from lunch and 133.7 (SD 8.1) g from dinner, reflecting the calculated higher intakes of energy from lunch (see Hudson, 1992). During Ramadan, the ninth month of the Moslem year (April/May in 1989), when a strict fast is observed during daylight for $30 \mathrm{~d}$, the average intake of starch from dinner was 159.4 (SD 0.4) $\mathrm{g}$, which is more than $3 \times$ SD above the mean for dinner in the other months, indicating that more food was cooked than usual at these meals to compensate for the daylight fasting.

The values given here are for total starch. Starch is not all digested and absorbed in the small intestine and, therefore, any calculation of the contribution of starch to energy intakes can be made properly only when measurements are made of the various types of starch with respect to their digestibility in vivo (Englyst et al. 1992a), but such measurements were beyond the scope of the present study. The presence of starch that escapes digestion and absorption in the small intestine (resistant starch; Englyst et al. 1992a) is often the result of food processing, and the amounts are not large in European diets (approximately 3-6 g/person per d; EURESTA, 1993). There is no reason to suppose that the values would be any higher for African diets. 


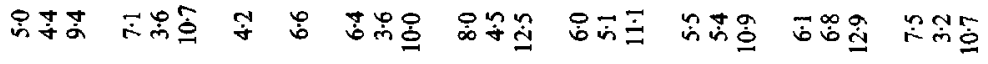

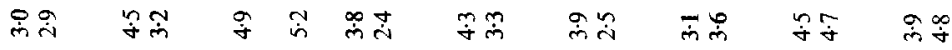

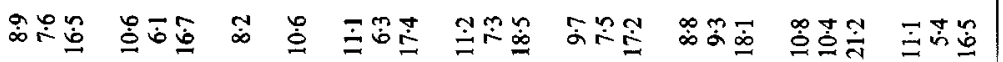
| 
STARCH AND NSP INTAKES IN WEST AFRICA

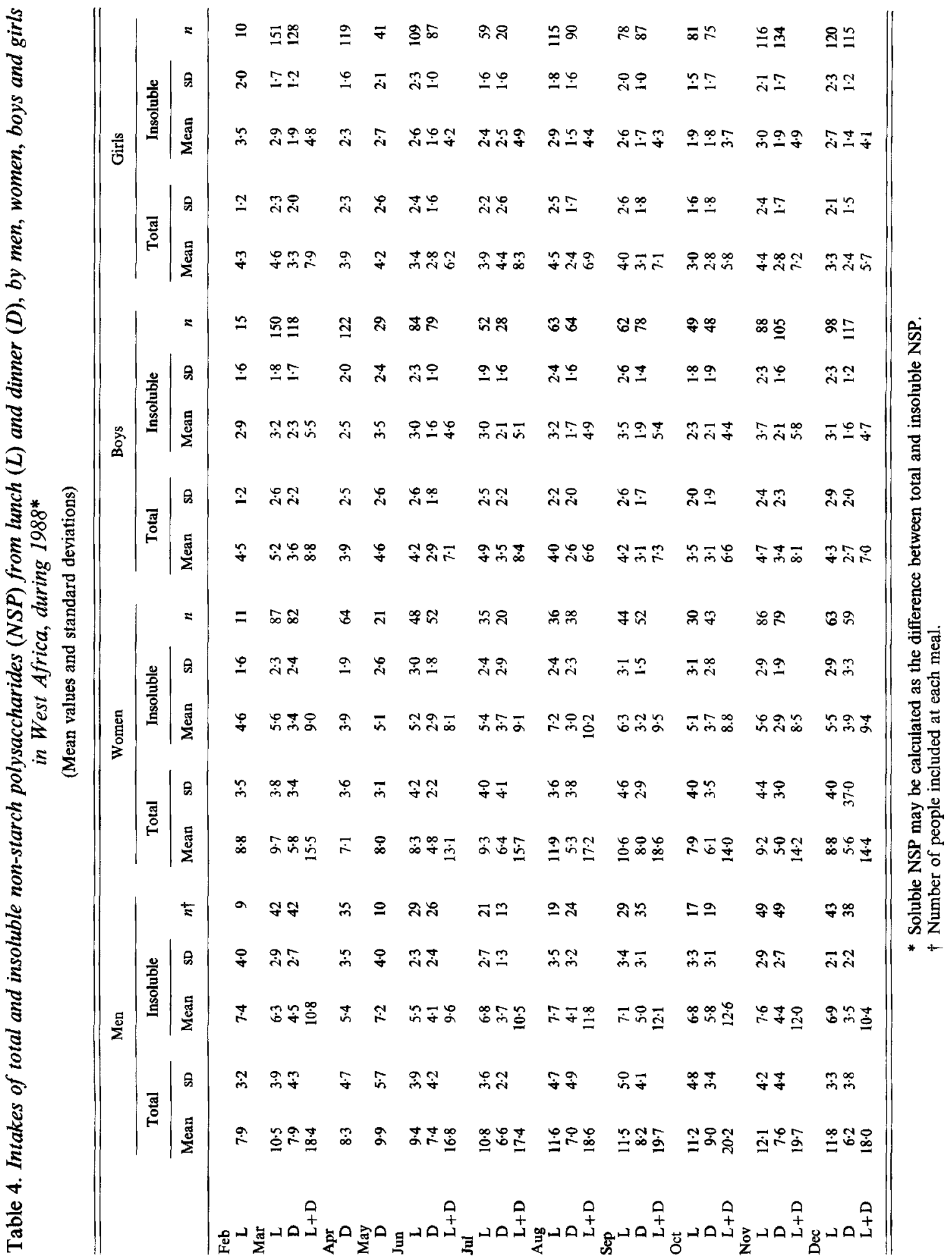


Table 5. Intakes of total and insoluble non-starch polysaccharides (NSP) from lunch $(L)$ and dinner (D), by men, women, boys and girls in West Africa, during 1989*

(Mean values and standard deviations)

\begin{tabular}{|c|c|c|c|c|c|c|c|c|c|c|}
\hline & \multicolumn{5}{|c|}{ Men } & \multicolumn{5}{|c|}{ Women } \\
\hline & \multicolumn{2}{|c|}{ Total } & \multicolumn{2}{|c|}{ Insoluble } & \multirow[b]{2}{*}{$n \dagger$} & \multicolumn{2}{|c|}{ Total } & \multicolumn{2}{|c|}{ Insoluble } & \multirow[b]{2}{*}{$n$} \\
\hline & Mean & SD & Mean & SD & & Mean & SD & Mean & SD & \\
\hline \multicolumn{11}{|l|}{ Jan } \\
\hline L & $11 \cdot 4$ & $5 \cdot 3$ & 6.5 & $3 \cdot 1$ & 5 & $8 \cdot 7$ & 3.8 & 4.9 & $2 \cdot 1$ & 74 \\
\hline D & 7.0 & $4 \cdot 4$ & $3 \cdot 4$ & 1.8 & 56 & $5 \cdot 8$ & $3 \cdot 2$ & $3 \cdot 4$ & $2 \cdot 4$ & 78 \\
\hline $\bar{L}+\mathrm{D}$ & 18.4 & & $9 \cdot 9$ & & & $14 \cdot 5$ & & $8 \cdot 3$ & & \\
\hline \multicolumn{11}{|l|}{$\mathrm{Feb}$} \\
\hline $\mathrm{L}$ & $13 \cdot 2$ & $6 \cdot 2$ & 7.0 & $3 \cdot 2$ & 34 & $11 \cdot 3$ & 5.4 & $5 \cdot 9$ & $2 \cdot 6$ & 64 \\
\hline $\mathrm{D}$ & 7.6 & $3 \cdot 7$ & $4 \cdot 5$ & 3.0 & 31 & $8 \cdot 1$ & $6 \cdot 2$ & $4 \cdot 5$ & 3.6 & 68 \\
\hline $\mathrm{L}+\mathrm{D}$ & $20 \cdot 8$ & & $11 \cdot 5$ & & & $19 \cdot 4$ & & $10 \cdot 4$ & & \\
\hline \multicolumn{11}{|l|}{ Mar } \\
\hline L & $14 \cdot 8$ & $5 \cdot 0$ & 7.9 & $2 \cdot 6$ & 37 & $11 \cdot 8$ & $5 \cdot 4$ & $6 \cdot 4$ & $3 \cdot 1$ & 55 \\
\hline $\mathrm{D}$ & $10 \cdot 3$ & 7.0 & $5 \cdot 2$ & 3.7 & 34 & 8.9 & $6 \cdot 1$ & 4.9 & 3.9 & 59 \\
\hline $\mathrm{L}+\mathrm{D}$ & $25 \cdot 1$ & & $13 \cdot 1$ & & & $20 \cdot 7$ & & $11 \cdot 3$ & & \\
\hline \multicolumn{11}{|l|}{ Apr } \\
\hline D & $15 \cdot 7$ & $6 \cdot 4$ & $9 \cdot 3$ & 3.6 & 28 & $13 \cdot 7$ & 6.0 & 7.9 & 3.6 & 48 \\
\hline \multicolumn{11}{|l|}{ May } \\
\hline D & $11 \cdot 8$ & $6 \cdot 3$ & $6 \cdot 7$ & 40 & 33 & $10 \cdot 6$ & 6.5 & 5.6 & 3.4 & 46 \\
\hline \multicolumn{11}{|l|}{ Jun } \\
\hline L & 11.8 & $4 \cdot 8$ & 6.7 & $2 \cdot 7$ & 65 & $10 \cdot 2$ & $5 \cdot 4$ & $5 \cdot 3$ & $2 \cdot 5$ & 115 \\
\hline $\mathrm{D}$ & 6.4 & $3 \cdot 4$ & $3 \cdot 4$ & $1 \cdot 7$ & 64 & $5 \cdot 1$ & $3 \cdot 5$ & 2.7 & 1.8 & 104 \\
\hline $\mathrm{L}+\mathrm{D}$ & $18 \cdot 2$ & & $10 \cdot 1$ & & & $15 \cdot 3$ & & 8.0 & & \\
\hline \multicolumn{11}{|l|}{ Jul } \\
\hline L & $11 \cdot 1$ & $4 \cdot 2$ & $6 \cdot 3$ & $2 \cdot 6$ & 59 & $10 \cdot 5$ & $5 \cdot 6$ & 5.6 & $2 \cdot 6$ & 99 \\
\hline $\bar{D}$ & $8 \cdot 1$ & $4 \cdot 2$ & $4 \cdot 0$ & $2 \cdot 3$ & 68 & $6 \cdot 4$ & $4 \cdot 4$ & 3.5 & $2 \cdot 7$ & 100 \\
\hline $\bar{L}+\mathrm{D}$ & $19 \cdot 2$ & & $10 \cdot 3$ & & & $17 \cdot 0$ & & $9 \cdot 1$ & & \\
\hline \multicolumn{11}{|l|}{ Aug } \\
\hline L & $9 \cdot 1$ & $5 \cdot 5$ & $5 \cdot 1$ & $3 \cdot 2$ & 68 & $8 \cdot 3$ & $5 \cdot 2$ & $4 \cdot 5$ & 2.6 & 93 \\
\hline D & 7.6 & $5 \cdot 1$ & $4 \cdot 0$ & 2.7 & 55 & $6 \cdot 8$ & $4 \cdot 2$ & 3.6 & $2 \cdot 2$ & 67 \\
\hline $\mathbf{L}+\mathbf{D}$ & $16 \cdot 7$ & & $9 \cdot 1$ & & & $15 \cdot 1$ & & 8.1 & & \\
\hline \multicolumn{11}{|l|}{ Sep } \\
\hline L & $9 \cdot 7$ & $6 \cdot 0$ & $5 \cdot 1$ & $3 \cdot 2$ & 60 & $8 \cdot 9$ & $5 \cdot 2$ & $4 \cdot 7$ & $2 \cdot 8$ & 67 \\
\hline D & 6.8 & $3 \cdot 8$ & 3.6 & $2 \cdot 1$ & 45 & $6 \cdot 0$ & 3.7 & $3 \cdot 2$ & $2 \cdot 0$ & 49 \\
\hline $\mathrm{L}+\mathrm{D}$ & $16 \cdot 5$ & & 8.7 & & & 14.9 & & 7.9 & & \\
\hline \multicolumn{11}{|l|}{ Oct } \\
\hline L & $15 \cdot 2$ & $5 \cdot 5$ & 8.6 & $3 \cdot 1$ & 20 & $12 \cdot 7$ & $5 \cdot 6$ & $7 \cdot 0$ & 3.0 & 33 \\
\hline $\mathrm{D}$ & $7 \cdot 1$ & $4 \cdot 7$ & 3.8 & 2.8 & 18 & $8 \cdot 1$ & 4.9 & $4 \cdot 4$ & $2 \cdot 8$ & 25 \\
\hline $\bar{L}+\mathbf{D}$ & $22 \cdot 3$ & & $12 \cdot 4$ & & & $20 \cdot 8$ & & $11 \cdot 4$ & & \\
\hline \multicolumn{11}{|l|}{ Nov } \\
\hline L & 13.5 & 6.0 & $7 \cdot 3$ & $3 \cdot 2$ & 31 & $10 \cdot 4$ & $5 \cdot 9$ & $5 \cdot 7$ & $3 \cdot 3$ & 41 \\
\hline $\mathrm{D}$ & $9 \cdot 4$ & 5.5 & $5 \cdot 2$ & 2.9 & 20 & $5 \cdot 7$ & $3 \cdot 2$ & $3 \cdot 1$ & 1.7 & 32 \\
\hline $\mathbf{L}+\mathbf{D}$ & $22 \cdot 9$ & & $12 \cdot 5$ & & & $16 \cdot 1$ & & 8.8 & & \\
\hline \multicolumn{11}{|l|}{ Dec } \\
\hline $\mathbf{L}$ & $12 \cdot 3$ & $4 \cdot 3$ & $7 \cdot 1$ & $2 \cdot 5$ & 22 & $10-0$ & $5 \cdot 4$ & $5 \cdot 4$ & $2 \cdot 8$ & 31 \\
\hline$\overline{\mathbf{D}}$ & $14 \cdot 3$ & $7 \cdot 6$ & $7 \cdot 3$ & 3.8 & 19 & 9.9 & $6 \cdot 1$ & 5.4 & 3.6 & 27 \\
\hline $\mathbf{L}+\mathbf{D}$ & $26 \cdot 6$ & & $14 \cdot 4$ & & & 19.9 & & $10 \cdot 8$ & & \\
\hline
\end{tabular}


Table 5. (cont.)

\begin{tabular}{|c|c|c|c|c|c|c|c|c|c|c|}
\hline & \multicolumn{5}{|c|}{ Boys } & \multicolumn{5}{|c|}{ Girls } \\
\hline & \multicolumn{2}{|c|}{ Total } & \multicolumn{2}{|c|}{ Insoluble } & \multirow[b]{2}{*}{$n \dagger$} & \multicolumn{2}{|c|}{ Total } & \multicolumn{2}{|c|}{ Insoluble } & \multirow[b]{2}{*}{$n$} \\
\hline & Mean & SD & Mean & $\mathrm{SD}$ & & Mean & SD & Mean & SD & \\
\hline \multicolumn{11}{|l|}{ Jan } \\
\hline L & $4 \cdot 6$ & $2 \cdot 5$ & $2 \cdot 9$ & $1 \cdot 8$ & 117 & 3.9 & $2 \cdot 2$ & $2 \cdot 4$ & 1.5 & 136 \\
\hline $\mathrm{D}$ & $3 \cdot 3$ & $1 \cdot 8$ & 1.8 & $1 \cdot 2$ & 124 & 2.8 & 1.8 & 1.5 & 1.0 & 127 \\
\hline $\mathbf{L}+\mathrm{D}$ & 7.9 & & 4.7 & & & 6.7 & 3.9 & & & \\
\hline \multicolumn{11}{|l|}{$\mathrm{Feb}$} \\
\hline $\mathrm{L}$ & 5.0 & $2 \cdot 7$ & $3 \cdot 4$ & $2 \cdot 2$ & 95 & 5.0 & $2 \cdot 7$ & $3 \cdot 3$ & $2 \cdot 1$ & 111 \\
\hline D & $3 \cdot 8$ & $2 \cdot 5$ & $2 \cdot 4$ & $2 \cdot 1$ & 80 & 3.0 & 1.9 & 1.7 & $1 \cdot 3$ & $\begin{array}{r}111 \\
70\end{array}$ \\
\hline $\mathbf{L}+\mathbf{D}$ & 8.8 & & $5 \cdot 8$ & & & 8.0 & & $5 \cdot 0$ & & \\
\hline \multicolumn{11}{|l|}{ Mar } \\
\hline L & 5.7 & $2 \cdot 7$ & 4.0 & $2 \cdot 3$ & 87 & 5.8 & $2 \cdot 6$ & 3.7 & $2 \cdot 2$ & 134 \\
\hline D & 3.8 & $2 \cdot 3$ & $2 \cdot 4$ & 1.9 & 79 & $4 \cdot 1$ & $2 \cdot 5$ & 2.9 & 2.5 & 104 \\
\hline$\overline{\mathbf{L}}+\mathbf{D}$ & 9.5 & & $6 \cdot 4$ & & & 9.9 & & $6 \cdot 6$ & & \\
\hline \multicolumn{11}{|l|}{ Apr } \\
\hline D & 6.7 & $3 \cdot 2$ & 4.9 & $2 \cdot 7$ & 56 & $6 \cdot 3$ & $2 \cdot 7$ & $4 \cdot 4$ & $2 \cdot 3$ & 73 \\
\hline \multicolumn{11}{|l|}{ May } \\
\hline \multirow{2}{*}{\multicolumn{11}{|c|}{ Jun }} \\
\hline & & & & & & & & & & \\
\hline L & $5 \cdot 1$ & $2 \cdot 8$ & $3 \cdot 0$ & 1.9 & 127 & $4 \cdot 4$ & $2 \cdot 1$ & 3.0 & 1.9 & 179 \\
\hline $\mathrm{D}$ & $3 \cdot 0$ & 1.8 & 1.7 & $1 \cdot 3$ & 105 & 3.0 & 1.9 & 1.7 & 1.2 & 132 \\
\hline $\mathbf{L}+\mathrm{D}$ & $8 \cdot 1$ & & $4 \cdot 7$ & & & 7.4 & & $4 \cdot 7$ & & \\
\hline \multicolumn{11}{|l|}{ Jul } \\
\hline L & 4.9 & 2.8 & 3.0 & $2 \cdot 0$ & 121 & 4.9 & 3.0 & 3.0 & $2 \cdot 0$ & 180 \\
\hline D & 3.4 & 2.5 & 1.9 & 1.5 & 89 & $3 \cdot 3$ & $2 \cdot 2$ & 1.8 & 1.4 & 153 \\
\hline $\mathbf{L}+\mathbf{D}$ & $8 \cdot 3$ & & 4.9 & & & $8 \cdot 2$ & & 4.8 & & \\
\hline \multicolumn{11}{|l|}{ Aug } \\
\hline L & 4.5 & $2 \cdot 7$ & 2.5 & 1.6 & 112 & 3.8 & $2 \cdot 3$ & $2 \cdot 2$ & 1.5 & 162 \\
\hline D & 3.6 & $2 \cdot 7$ & $2 \cdot 1$ & 1.9 & 76 & $3 \cdot 7$ & 2.6 & 2.0 & 1.4 & 113 \\
\hline $\mathrm{L}+\mathrm{D}$ & $8 \cdot 1$ & & $4 \cdot 6$ & & & $7 \cdot 5$ & & $4 \cdot 2$ & & \\
\hline \multicolumn{11}{|l|}{ Sep } \\
\hline $\mathrm{L}$ & $5 \cdot 1$ & $2 \cdot 6$ & $3 \cdot 1$ & $2 \cdot 0$ & 63 & $5 \cdot 1$ & 2.8 & $2 \cdot 8$ & $1 \cdot 6$ & 99 \\
\hline $\mathrm{D}$ & 3.8 & $2 \cdot 4$ & $2 \cdot 2$ & 1.8 & 47 & $3 \cdot 0$ & 1.7 & 1.6 & 1.0 & 83 \\
\hline $\mathbf{L}+\mathrm{D}$ & 8.9 & & $5 \cdot 3$ & & & $8 \cdot 1$ & & $4 \cdot 4$ & & \\
\hline \multicolumn{11}{|l|}{ Oct } \\
\hline L & 5.2 & $3 \cdot 2$ & $3 \cdot 6$ & 2.5 & 37 & 4.9 & 2.9 & $3 \cdot 1$ & $2 \cdot 2$ & 86 \\
\hline D & $3 \cdot 3$ & 1.8 & 1.9 & 1.3 & 34 & 3.4 & $2 \cdot 6$ & $2 \cdot 0$ & 1.7 & 53 \\
\hline $\mathbf{L}+\mathrm{D}$ & 8.5 & & 5.5 & & & $8 \cdot 3$ & & $5 \cdot 1$ & & \\
\hline \multicolumn{11}{|l|}{ Nov } \\
\hline L & 5.9 & 3.0 & $3 \cdot 4$ & 1.7 & 61 & 5.7 & $2 \cdot 8$ & $3 \cdot 2$ & 1.7 & 85 \\
\hline $\bar{D}$ & 2.8 & 1.6 & $2 \cdot 3$ & $2 \cdot 2$ & 32 & $3 \cdot 2$ & $1 \cdot 8$ & 2.0 & 1.5 & 58 \\
\hline $\mathrm{L}+\mathrm{D}$ & 8.7 & & $5 \cdot 7$ & & & 8.9 & & $5-2$ & & \\
\hline \multicolumn{11}{|l|}{ Dec } \\
\hline L & 5.0 & 2.6 & 3.6 & $2 \cdot 4$ & 45 & 5.2 & $2 \cdot 6$ & $3 \cdot 1$ & 1.8 & 85 \\
\hline $\mathrm{D}$ & $4 \cdot 2$ & 2.9 & 2.9 & $2 \cdot 3$ & 39 & 5.0 & $3 \cdot 0$ & $3 \cdot 3$ & $2 \cdot 3$ & 60 \\
\hline $\mathrm{L}+\mathrm{D}$ & 9.2 & & 6.5 & & & $10 \cdot 2$ & & $6 \cdot 4$ & & \\
\hline
\end{tabular}

* Soluble NSP may be calculated as the difference between total and insoluble NSP.

$\dagger$ Number of people included at each meal. 
Table 6. Overall mean intakes of non-starch polysaccharides (NSP) from two cooked meals per day, by men, women, boys and girls in West Africa during the years 1987-1989*

\begin{tabular}{|c|c|c|c|c|}
\hline & Men & Women & Boys & Girls \\
\hline \multicolumn{5}{|c|}{ Total NSP } \\
\hline 1987 & 17.8 & $15 \cdot 3$ & 8.2 & 7.7 \\
\hline 1988 & 18.6 & $15 \cdot 3$ & $7 \cdot 5$ & 6.9 \\
\hline 1989 & $18 \cdot 7$ & 17.4 & $8 \cdot 6$ & $8 \cdot 3$ \\
\hline \multicolumn{5}{|c|}{ Insoluble NSP } \\
\hline 1987 & 11.0 & 9.4 & $5 \cdot 6$ & $5 \cdot 1$ \\
\hline 1988 & 11.2 & $9 \cdot 1$ & $5 \cdot 1$ & $4 \cdot 4$ \\
\hline 1989 & $11 \cdot 2$ & $9 \cdot 4$ & $5 \cdot 4$ & 5.0 \\
\hline \multicolumn{5}{|c|}{ Soluble NSP } \\
\hline 1987 & 6.8 & 5.9 & $2 \cdot 6$ & $2 \cdot 6$ \\
\hline 1988 & $7 \cdot 4$ & 6.2 & $2 \cdot 4$ & $2 \cdot 5$ \\
\hline 1989 & 7.5 & 8.0 & $3 \cdot 2$ & $3 \cdot 3$ \\
\hline
\end{tabular}

* Values are intakes of NSP from lunch and dinner $(\mathrm{g} / \mathrm{d})$ calculated as the average of the mean monthly values in Tables $3-5$ where there are values for both meals $(1987, n 8 ; 1988, n 8 ; 1989, n 10)$.

\section{Fibre measurement}

Following the principles laid down by Southgate $(1969 a, b)$, methodology has been developed for the measurement of NSP, with identification and measurement of the constituent sugars by gas-liquid chromatography or high-pressure liquid chromatography (Englyst et al. 1982, 1992 b, 1994; Quigley \& Englyst, 1992, 1994), as the best index of the plant cell-wall material (dietary fibre) present in foods. The different physiological effects that result from the ingestion of NSP are related to the physical and chemical properties of the carbohydrates. For this reason it is appropriate to divide NSP into soluble and insoluble fractions, which have demonstrably different effects in man. For example, ingestion of apple pectin or oat bran, which are rich in soluble NSP, has only a small effect on faecal bulk. In contrast, ingestion of wheat bran, which is rich in insoluble NSP, results in a very substantial increase in faecal bulk (Kay \& Truswell, 1980; Story \& Kelley, 1982).

Samples of raw food were collected in Keneba, freeze-dried where appropriate, and sent to Cambridge for analysis by the Englyst et al. (1992b) GLC procedure. The values obtained for the soluble and insoluble NSP contents of these Gambian foods are given in Table 2. Values for the constituent neutral sugars and uronic acids will be published elsewhere.

\section{Polysaccharide intakes}

The analytically determined values for NSP were included in the database for food composition, and dietary intakes from two cooked meals/d were calculated by the same arithmetic as that used for the calculation of energy intakes (Hudson 1992, 1995). The results are given in Tables 3-5 and are summarized in Table 6. There remains the question of interpretation of these intake values. No attempt was made to measure total food intake in this study; two cooked meals/d were included but no record was made of snack foods. The values calculated for the energy intake of adult males were about $80 \%$ of the values recorded for total energy expenditure in January, April and July, when there was little change in either of these values or in body weight (Hudson, 1992). The calculated value for 
energy intake in October was little different but energy expenditure was increased with concomitant loss of body weight.

Comparison of total energy expenditure, as measured by the doubly labelled water technique, and estimated energy intake from cooked meals suggests that the intake estimates are of the order of $80 \%$ of total energy intake (Hudson, 1992, 1995). Estimation of polysaccharide intakes, however, is problematic in the absence of both data for the intake of snack foods and an independent measurement of total intake for reference.

The difference between energy intake and total energy expenditure is of the order of $2100 \mathrm{~kJ} / \mathrm{d}$ for men, and it is possible to calculate the consequences for NSP intake if that amount of energy was to be provided by a single snack food. The energy density of fruit and vegetables is generally low, so that substantial amounts would have to be eaten to provide $2100 \mathrm{~kJ}$, e.g. about $900 \mathrm{~g}$ ripe mango or more than $1.5 \mathrm{~kg}$ raw carrot would have to be eaten every day for a year. These are unrealistically large amounts; these foods are available only at certain times of the year and then not in these quantities.

Only a very few of the families in Keneba can afford to buy bread from the village baker or milk from the local cattle herders. If bread were the sole source of the extra energy intake, the NSP contribution to the diet would be of the order of $3 \mathrm{~g}$ total NSP/d, and if milk were the sole source of the extra energy there would be no increase in NSP intake. If groundnuts were the sole source of the extra energy, $2100 \mathrm{~kJ} / \mathrm{d}$ would be provided by about $90 \mathrm{~g}$ nuts, and this would contribute about $6 \mathrm{~g}$ total NSP/d.

Most people eat a variety of snack foods throughout the year. For example, women make dempetengo (pounded and roasted rice) in the fields for immediate consumption when they are harvesting their rice crops. They may eat considerable quantities of this dempetengo at a time, but the consumption is limited to a few days each year. Maize is one of the first crops to mature, and whole cobs are roasted and eaten immediately. Again, individuals may eat considerable quantities, but this food is available only from about the middle of August to the middle of September. Vegetables are grown in gardens but most of these are cooked; carrots are eaten raw but are available only from March to May, and then not in large quantities. Some foods are taken from the bush, but these foods are available only seasonally, e.g. mangoes are available from March to July and bush cassava from the end of September to the end of November. Bread, milk and the home-made pastries of various sorts that are sometimes available for purchase in the village are available only to the comparatively wealthy few. Groundnuts, however, are grown by almost every family in Keneba, both for food and as a cash crop. The groundnuts are harvested, dried and stored for long periods, and are available as snack food throughout the year.

No reliable data exist for the consumption of snack foods in this community. However, groundnuts offer the commonest source of snack food, and these could supply the extra $2100 \mathrm{~kJ} / \mathrm{d}$ if consumed in realistic amounts. Other snack foods are available, but only seasonally and in small quantities, so it seems unlikely that they will contribute significant amounts of NSP over the course of a year. It seems reasonable to suggest that the contribution from snack foods is therefore of the order of $6 \mathrm{~g}$ total NSP/d for an adult male.

Intake values of the order of $12 \mathrm{~g}$ total NSP/d have been reported for UK adults (Bingham et al. 1990) and the insoluble: soluble NSP ratio in the UK diet is not far removed from unity; by comparison, intake values for total NSP from cooked food alone are close to $19 \mathrm{~g} / \mathrm{d}$ for adult males in the present study, and there is a preponderance of insoluble NSP in the diet. If groundnuts were to represent the majority of snack foods, then the preponderance of insoluble NSP would remain and intakes would be estimated to be of the order of $25 \mathrm{~g}$ total NSP/d for an adult male. Consumption of fruit and vegetables, where 
insoluble:soluble NSP ratio approaches 0.5 , would tend to decrease the overall insoluble: soluble NSP ratio in the whole diet, which was close to 1.5 for cooked foods (1.6 in $1987 ; 1.5$ in $1988 ; 1.5$ in 1989). However, this effect of fruit and vegetables is likely to be small for the whole diet over the course of a year because of the small amounts eaten.

The contribution of snack foods to total starch intakes is not expected to be quantitatively significant. The cereals in cooked food are the components of the diet with the highest starch contents. The consumption of $90 \mathrm{~g}$ groundnuts/d would contribute about $30 \mathrm{~g}$ starch, i.e. of the order of $10 \%$ of the estimated starch intake from cooked food. A few of the other snack foods could individually contribute rather more starch, e.g. bush cassava contains about $750 \mathrm{~g}$ starch $/ \mathrm{kg}$ on a dry matter basis, but these foods are available for only brief periods and in very limited quantities.

These are believed to be the first detailed data for polysaccharide intake in West Africa, and are certainly the first West African data where the intake methodology has been validated by field use of the doubly labelled water method for the measurement of total energy expenditure.

The majority of the fieldwork was done by MRC Gambian fieldworkers as a team ably led by $\mathrm{Mr}$ Baba S. N. Jobarteh. We are very grateful to Mrs E. Collinson for her help with the NSP measurements and to Dr S. Kingman for her help with the starch measurements.

\section{REFERENCES}

Anderson, T. L., Heird, W. C. \& Winters, R. W. (1977). Clinical and physiological consequences of total parenteral nutrition in the paediatric patient. In Current Concepts in Parenteral Nutrition, pp. $111-127$ [J. M. Greep, P. B. Soeters, R. I. C. Westdorp, C. W. R. Phaf and J. E. Fischer, editors]. The Hague: Nijhoff Medical Division.

Bingham, S. A., Pett, S. \& Day, K. C. (1990). Non-starch polysaccharide intake of a representative sample of British adults. Journal of Human Nutrition and Dietetics 3, 333-337.

Englyst, H. N. \& Kingman, S. M. (1990). Dietary fibre and resistant starch. A nutritional classification of plant polysaccharides. In Dietary Fiber, pp. 49-65 [D. Kritchevsky, C. Bonfield and J. W. Anderson, editors]. New York: Plenum Press.

Englyst, H. N., Kingman, S. M. \& Cummings, J. H. (1992a). Classification and measurement of nutritionally important starch fractions. European Journal of Clinical Nutrition 46, Suppl. 2, S33-S50.

Englyst, H. N., Quigley, M. E. \& Hudson, G. J. (1994). Determination of dietary fibre as non-starch polysaccharides with gas-liquid chromatographic, high-performance liquid chromatographic or spectrophotometric measurement of constituent sugars. Analyst 119, 1497-1509.

Englyst, H. N., Quigley, M. E., Hudson, G. J. \& Cummings, J. H. (1992b). Determination of dietary fibre as nonstarch polysaccharides by gas-liquid chromatography. Analyst 117, 1707-1714.

Englyst, H. N., Wiggins, H. S. \& Cummings, J. H. (1982). Determination of the non-starch polysaccharides in plant foods by gas-liquid chromatography of constituent sugars as alditol acetates. Analyst 107, 307-318.

EURESTA (1993). European FLAIR-concerted action on resistant starch. Physiological implications of the consumption of resistant starch in man. Newsletter IV (2). Wageningen: Wageningen Agricultural University.

Hudson, G. J. (1992). Food intake in a West African village. PhD thesis, CNAA, London.

Hudson, G. J. (1995). Food intake in a West African village. Estimation of food intake from a shared bowl. British Journal of Nutrition 73, 551-569.

Kay, R. M. \& Truswell, A. S. (1980). Dietary fiber: effects on plasma and biliary lipids in man. In Medical Aspects of Dietary Fiber, pp. 153-173 [G. A. Spiller and R. M. Kay, editors]. New York: Plenum.

Quigley, M. \& Englyst, H. N. (1992). Measurement of neutral sugars and uronic acids by high-pressure liquid chromatography with pulsed amperometric detection. Analyst 117, 1715-1718.

Quigley, M. E. \& Englyst, H. N. (1994). Determination of the uronic acid constituents of non-starch polysaccharides by high-performance liquid chromatography with pulsed amperometric detection. Analyst 119, $1511-1518$.

Southgate, D. A. T. (1969a). Determination of carbohydrates in foods. I. Available carbohydrates. Journal of the Science of Food and Agriculture 20, 326-330.

Southgate, D. A. T. $(1969 \mathrm{~b})$. Determination of carbohydrates in foods. II. Unavailable carbohydrates. Journal of the Science of Food and Agriculture 20, 331-335.

Story, J. A. \& Kelley, M. J. (1982). Dietary fiber and lipoproteins. In Dietary Fiber in Health and Disease, pp. 229-236 [G. V. Vahouny and D. Kritchevsky, editors]. New York: Plenum. 